\title{
Efficacy and safety of bevacizumab in elderly patients with metastatic colorectal cancer: results from the Czech population-based registry
}

Lubomir Slavicek , Tomas Pavlik², Jiri Tomasek³, Zbynek Bortlicek², Tomas Buchler ${ }^{4}$, Bohuslav Melichar ${ }^{5}$, Rostislav Vyzula ${ }^{3}$, Jana Prausova ${ }^{6}$, Jindrich Finek', Ondrej Majek ${ }^{2}$ and Ladislav Dusek ${ }^{2^{*}}$

\begin{abstract}
Background: Patients aged 65 years and older represent the majority of patients with metastatic colorectal cancer (mCRC). However, this patient population is often underrepresented in clinical trials and probably undertreated in the clinical practice.

Methods: We have analysed the outcomes of 3,187 mCRC patients treated with first-line bevacizumab based on data from the Czech national registry of mCRC patients aiming to compare the treatment efficacy and safety according to the age categories.

Results: In total, 2,126 (66.7\%), 932 (29.2\%), and 129 (4.0\%) patients were aged <65 years, 65 to 75 years, and $75+$ years, respectively. Median progression-free survival (PFS) was 11.4, 11.3, and 11.8 months for patients aged $<65$ years, 65 to 75 years, and $75+$ years, respectively ( $p=0.94)$. Median overall survival (OS) was 26.9, 27.5, and 25.1 months for patients aged $<65$ years, 65 to 75 years, and $75+$ years, respectively $(p=0.73)$. Using multivariable Cox model for both PFS and OS, the patient age was not significantly associated with either PFS or OS. No increase in bevacizumab-related toxicity was observed among the elderly mCRC patients with the exception of hypertension, which was observed in 71 (3.3\%), 34 (3.6\%), and 10 (7.8\%) patients aged <65 years, 65 to 75 years, and 75+ years, respectively.

Conclusions: The results of the present study suggest similar outcome in terms of OS and PFS with bevacizumab-containing therapy in elderly mCRC patients fit for chemotherapy combined with targeted therapy compared to younger patients. Thus, chronological age should not be considered to represent a limitation in prescribing bevacizumab-containing therapy in mCRC patients.
\end{abstract}

Keywords: Anti-angiogenic therapy, Chemotherapy, Elderly patients, Overall survival, Progression-free survival

\section{Background}

Colorectal cancer (CRC) represents a serious public health problem in the Czech Republic as the Czech population presently ranks $3^{\text {rd }}$ in international statistics of agestandardised CRC incidence rates, with 78 new cases of CRC being diagnosed annually per 100,000 inhabitants (2010) [1]. In addition, more than one quarter of these patients have metastatic disease at the time of diagnosis [2]. Over the past decade, however, the introduction of new cytotoxic drugs, targeted therapy, and an increase in

\footnotetext{
* Correspondence: dusek@iba.muni.cz

${ }^{2}$ Institute of Biostatistics and Analyses, Masaryk University, Brno, Czech Republic

Full list of author information is available at the end of the article
}

the use of liver resection have resulted in significantly improved outcomes in metastatic CRC (mCRC) patients $[3,4]$. Monoclonal antibodies, the targeted agents currently used in the treatment of mCRC are usually utilised in combination with cytotoxic drugs. The first and currently most widely used monoclonal antibody in mCRC therapy is bevacizumab (F. Hoffman-La Roche Ltd., Basel, Switzerland), a drug targeting the vascular endothelial growth factor. Efficacy and safety of bevacizumab administered in combination with chemotherapy backbone regimens in patients with $\mathrm{mCRC}$ have been the subject of several randomised clinical trials [5-7] as well as observational studies [8,9]. Although patients $\geq 65$ years of age represent the majority of patients with $\mathrm{mCRC}$, this 
patient population is often underrepresented in clinical trials and very likely undertreated in the clinical practice $[10,11]$. However, the results of recently published randomised trials as well as observational studies [12-15] suggest that bevacizumab provides similar overall survival (OS) and progression-free survival (PFS) benefits in patients aged $\geq 65$ years compared to younger patients.

In the present study, we have analysed the data from the Czech national registry of $\mathrm{mCRC}$ patients treated with first-line bevacizumab with the aim to compare the treatment outcomes according to age.

\section{Methods \\ Patients}

Adult mCRC patients treated with first-line bevacizumabcontaining therapy in the Czech Republic were included in the present analysis. In the Czech Republic, the administration of targeted therapy is concentrated to comprehensive cancer centres and these drugs are reimbursed only when administered in one of these centres. The data set was obtained from the Czech population-based, retrospective, observational CORECT registry [16] which contains de-identified data of the Czech mCRC patients treated with targeted therapies including bevacizumab, cetuximab, and panitumumab. The protocol was approved by the independent ethics committee at each participating centre (Ethics Committee (EC) of the Ceske Budejovice Hospital, EC of the Chomutov Hospital, EC of the General University Hospital in Prague, EC of the Jihlava Hospital, EC of the Liberec Regional Hospital, EC of the Masaryk Hospital in Usti nad Labem, EC of the Masaryk Memorial Cancer Institute in Brno, EC of the Na Bulovce Hospital in Prague, EC of the Na Homolce Hospital in Prague, EC of the Novy Jicin Hospital, EC of the Pardubice Regional Hospital, EC of the St. Anne's University Hospital (UH) in Brno, EC of the Thomayer Hospital in Prague, EC of the Tomas Bata Regional Hospital in Zlin, EC of the UH Brno, EC of the UH Hradec Kralove, EC of the UH in Motol, Prague, EC of the UH Olomouc, EC of the UH Ostrava, EC of the UH Pilsen) and complied with the International Ethical Guidelines for Biomedical Research Involving Human Subjects, Good Clinical Practice guidelines, the Declaration of Helsinki, and local laws. Based on the recent validation using the data of all health care payers in the Czech Republic, the CORECT database includes data of approximately $96 \%$ of all mCRC patients treated with targeted therapies in the country. The data are entered into the CORECT database by the clinicians and updated at least twice yearly. The final data cut-off date was 30 September 2012.

\section{Outcome assessment}

Both OS and PFS were considered the primary efficacy measures in the present study. Objective response was assessed using the RECIST criteria. Both OS and PFS were calculated from the start of bevacizumab-containing therapy. Only patients who started bevacizumab and chemotherapy at least six months prior to the data cut-off were included in the present analysis. Such design ensured sufficient follow-up for statistically relevant analyses of the time-to-event endpoints.

Adverse events were assessed using the Common Terminology Criteria for Adverse Events (CTCAE) version 3.0 criteria. The severity of adverse events was classified by the attending medical oncologist as 'mild to moderate' corresponding to grade 1 to 2 toxicity or 'severe' corresponding to grade 3 to 4 toxicity. Only toxicities considered to be related to the administration of bevacizumab therapy were entered into the database.

In accordance with the World Health Organization, elderly mCRC patients were defined as persons aged $\geq 65$ years. In some studies, however, the cut-off to define elderly population was set at age of 75 years. Therefore, in the present study outcomes were analysed based on the patients'age at the start of bevacizumab therapy in following subgroups: (1) <65 years, (2) 65 to 75 years, and (3) $\geq 75$ years.

\section{Statistical analysis}

Standard descriptive statistics were used to characterise the data. Differences in categorical parameters as well as in the incidence of adverse effects among age categories were assessed using the Pearson chi-square test. Comparisons of continuous variables were based on the Kruskal-Wallis test. The survival was estimated using the Kaplan-Meier method. Log-rank test was used to compare OS and PFS for different subgroups. Multivariable Cox proportional hazards model was used to assess the effect of age on survival in the presence of other potential predictive and prognostic factors. Standard level of significance $\alpha=0.05$ was used.

\section{Results}

In total, 3,187 mCRC patients treated with first-line bevacizumab were analysed. Of those, 2,126 (66.7\%), 932 (29.2\%), and $129(4.0 \%)$ patients were age $<65$ years, 65 to 75 years, and $\geq 75$ years, respectively. Baseline patient characteristics are shown in Table 1. As of 30 September 2012, the median follow-up was 17 months (range 0.5-84.6 months) with 209 (9.8\%), 110 (11.8\%), and $17(13.2 \%)$ patients aged $<65$ years, 65 to 75 years, and $\geq 75$ years remaining on bevacizumab-containing therapy, respectively. Median duration of bevacizumab therapy was 7.4 months (range 0.5-58.7 months), 6.9 months (range 0.5-41.7 months), and 6.4 months (range 0.531.0 months) in the $<65$ years, 65 to 75 years, and $\geq 75$ years age cohorts, respectively. 
Table 1 Baseline characteristics of analysed patients

\begin{tabular}{|c|c|c|c|c|}
\hline Characteristic & $<65$ years $(n=2,126)$ & $65-75$ years $(n=932)$ & $\geq 75$ years $(n=129)$ & p-value ${ }^{a}$ \\
\hline Males, n (\%) & $1,324(62.3)$ & $593(63.6)$ & $79(61.2)$ & 0.74 \\
\hline \multicolumn{5}{|l|}{ Age at treatment initiation } \\
\hline Median (min-max) & $57.7(21.3-64.9)$ & $68.3(65.0-74.9)$ & $76.9(75.0-85.2)$ & - \\
\hline \multicolumn{5}{|l|}{ Localization, n (\%) } \\
\hline Colon & $1,287(60.5)$ & $571(61.3)$ & $84(65.1)$ & 0.57 \\
\hline Rectum & $839(39.5)$ & $361(38.7)$ & $45(34.9)$ & \\
\hline History of thromboembolism, $n(\%)$ & $68(3.2)$ & $55(5.9)$ & $7(5.4)$ & 0.002 \\
\hline History of hypertension, n (\%) & $629(29.6)$ & $494(53.0)$ & $85(65.9)$ & $<0.001$ \\
\hline \multicolumn{5}{|l|}{ Primary metastatic, n (\%) } \\
\hline Mo & $804(37.8)$ & $389(41.7)$ & $55(42.6)$ & 0.09 \\
\hline M1 & $1,322(62.2)$ & $543(58.3)$ & $74(57.4)$ & \\
\hline Adenocarcinoma, n (\%) & $2,060(96.7)$ & $916(98.3)$ & $127(98.4)$ & 0.07 \\
\hline Prior surgery, n (\%) & $1,690(79.5)$ & $808(86.7)$ & $117(90.7)$ & $<0.001$ \\
\hline Prior radiotherapy, n (\%) & 437 (20.6) & $200(21.5)$ & $17(13.2)$ & 0.09 \\
\hline Adjuvant chemotherapy, n (\%) & $639(30.1)$ & $302(32.4)$ & $39(30.2)$ & 0.43 \\
\hline \multicolumn{5}{|l|}{ Site of metastatic disease, $\mathrm{n}(\%)$} \\
\hline Liver & $1,348(63.4)$ & $594(63.7)$ & $99(76.7)$ & 0.009 \\
\hline Lung & $504(23.7)$ & $240(25.8)$ & $31(24.0)$ & 0.48 \\
\hline Other & $933(43.9)$ & $390(41.8)$ & $41(31.8)$ & 0.02 \\
\hline \multicolumn{5}{|l|}{ Number of metastatic sites, $\%$} \\
\hline $1 / 2 />2$ & $55.5 / 31.2 / 13.3$ & $58.6 / 31.8 / 9.6$ & $62.7 / 30.2 / 7.1$ & 0.02 \\
\hline \multicolumn{5}{|l|}{ Chemotherapy regimens, n (\%) } \\
\hline FOLFOX & $903(42.5)$ & $394(42.3)$ & $51(39.5)$ & $<0.001$ \\
\hline XELOX & $753(35.4)$ & $313(33.6)$ & $25(19.4)$ & \\
\hline FOLFIRI & $199(9.4)$ & $74(7.9)$ & $5(3.9)$ & \\
\hline XELIRI & $127(6.0)$ & $39(4.2)$ & $1(0.8)$ & \\
\hline Capecitabine & $39(1.8)$ & $44(4.7)$ & $18(14.0)$ & \\
\hline 5-FU/LV & $21(1.0)$ & $21(2.3)$ & $23(17.8)$ & \\
\hline Other & $67(3.2)$ & $32(3.4)$ & $3(2.3)$ & \\
\hline Without CT & $17(0.8)$ & $15(1.6)$ & $3(2.3)$ & \\
\hline \multicolumn{5}{|l|}{ PS at bevacizumab initiation, $\mathrm{n}(\%)$} \\
\hline 0 & $612(28.8)$ & $256(27.5)$ & $41(31.8)$ & 0.02 \\
\hline 1 & $549(25.8)$ & $279(29.9)$ & $39(30.2)$ & \\
\hline $2-3$ & $24(1.1)$ & $15(1.6)$ & $6(4.7)$ & \\
\hline Not available & $941(44.3)$ & $382(41.0)$ & $43(33.3)$ & \\
\hline \multicolumn{5}{|l|}{ Treatment duration (months) } \\
\hline Median (min- max) & $7.4(0.5-58.7)$ & $6.9(0.5-41.7)$ & $6.4(0.5-31.0)$ & 0.04 \\
\hline \multicolumn{5}{|l|}{ Best response, $n(\%)$} \\
\hline$C R$ & $332(15.6)$ & $112(12.0)$ & $8(6.2)$ & 0.003 \\
\hline$P R$ & $675(31.7)$ & $271(29.1)$ & $40(31.0)$ & \\
\hline SD & $741(34.9)$ & 381 (40.9) & $59(45.7)$ & \\
\hline PD & $248(11.7)$ & $107(11.5)$ & $12(9.3)$ & \\
\hline Not available & $130(6.1)$ & $61(6.5)$ & $10(7.8)$ & \\
\hline
\end{tabular}

aruskal-Wallis test was used for age at treatment initiation and treatment duration, Pearson chi-square test for the rest of variables. 


\section{Chemotherapy regimens}

In most patients across all age subgroups $(n=2,439$, $76.5 \%$ ), bevacizumab was administered in combination with oxaliplatin-based chemotherapy backbone regimens including infusional 5-fluorouracil/leucovorin/oxaliplatin (FOLFOX) and capecitabine/oxaliplatin (XELOX) (Table 1). However, while the percentage of mCRC patients receiving FOLFOX was approximately identical in all age groups, a trend toward decreased use of XELOX in patients aged $\geq 75$ years was observed. In addition, chemotherapy regimens containing irinotecan were less frequently used in patients aged $\geq 75$ years. On the other hand, fluoropyrimidine monotherapy was more likely to be used as chemotherapy backbone in patients aged $\geq 75$ years, and $17.8 \%$ and $14.0 \%$ of these patients received a 5 fluororuracil/leucovorin (5-FU/LV) regimen or capecitabine, respectively.

\section{Survival outcomes}

Median PFS was 11.4 months (95\% confidence interval [CI] 10.9-11.9 months) for patients aged $<65$ years, 11.3 months (95\% CI 10.5-12.0 months) for patients aged 65 to 75 years, and 11.8 months ( $95 \%$ CI 9.6-14.0 months) for patients $\geq 75$ years (Figure 1). The PFS differences between age categories were not statistically significant $(\mathrm{p}=0.94)$. Median OS was 26.9 months $(95 \%$ CI 25.328.5 months) for patients aged $<65$ years, 27.5 months (95\% CI 25.0-29.9 months) for patients aged 65 to 75 years, and 25.1 months (95\% CI 11.3-38.9 months) for patients aged $\geq 75$ years (Figure 2 ). No statistically

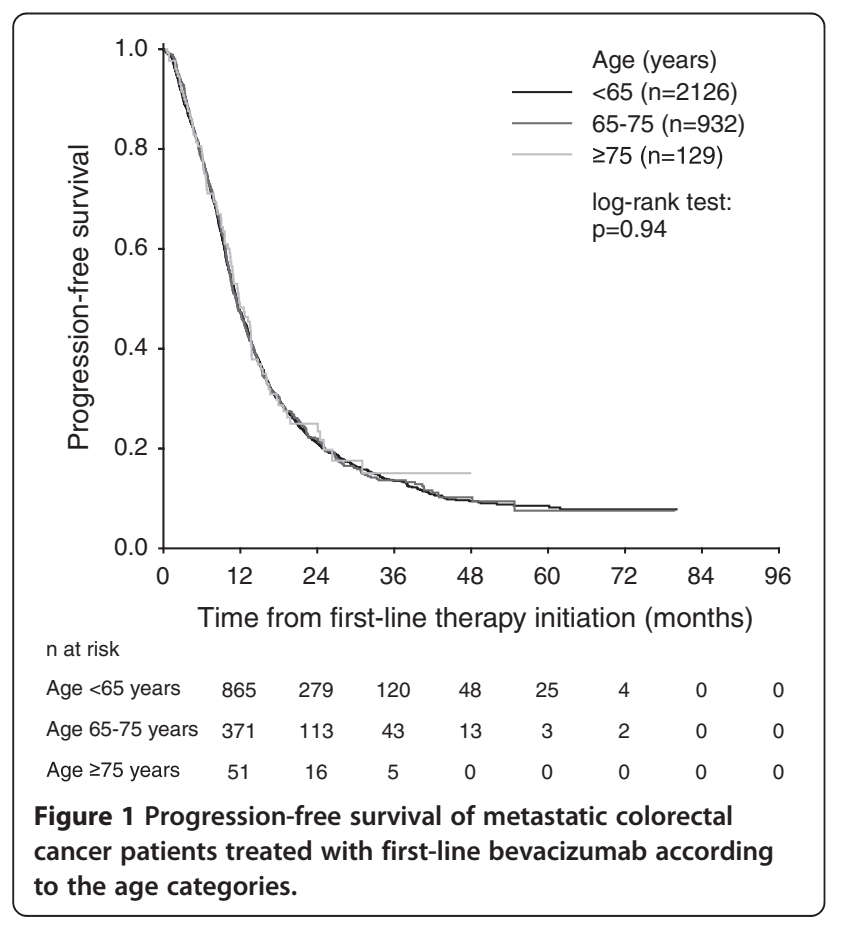

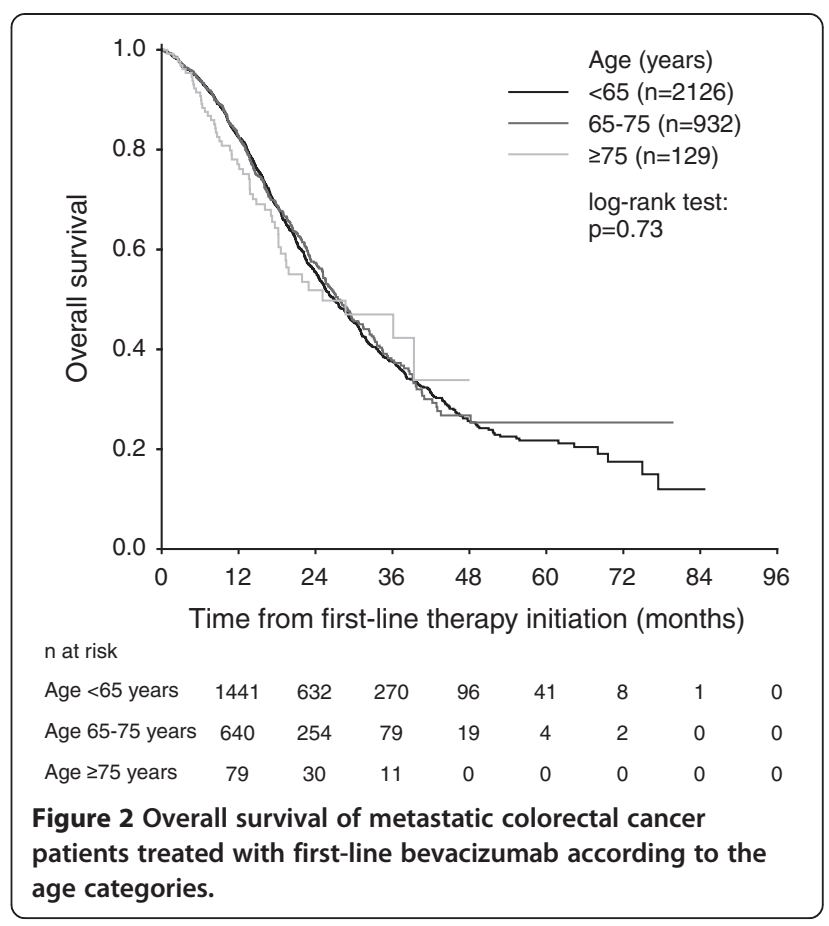

significant differences in OS were observed between the age groups $(\mathrm{p}=0.73)$. PFS and OS estimates according to age categories and chemotherapy backbone regimens are presented in Table 2.

In order to adjust for the effect of other potential predictive and prognostic factors that may be associated with age, multivariable Cox model for both PFS and OS was designed (Table 3). Similarly to the univariate analysis, the patient age was not significantly associated with PFS in the multivariable model. When patients $<65$ years were used as the reference, the hazard ratio (HR) was estimated to be $0.99(\mathrm{p}=0.88)$ and $1.01(\mathrm{p}=0.96)$ in patients aged 65 to 75 years and patients aged $\geq 75$ years, respectively (Table 3 ). Variables significantly associated with PFS in the final model included the presence of two and more metastatic sites, synchronous mCRC, and rectal primary.

Similarly, in the multivariable Cox model for OS (Table 3), the patient age was not significantly associated with OS (patients aged 65 to 75 years: $H R=0.98, p=0.73$; patients aged $\geq 75$ years: $H R=1.18, p=0.24$ ). On the other hand, the number of metastatic sites, the presence of metastatic disease at the diagnosis of CRC, and the site of primary tumour were observed to be the strongest independent predictors of OS. Patients with three and more metastatic sites at the start of bevacizumab therapy were found to have almost two times higher risk of death compared to patients with only one metastatic site, and in patients with two metastatic sites the risk of death was increased by more than $40 \%$. Patients with synchronous 
Table 2 Progression-free survival (PFS) and overall survival (OS) according to age categories and chemotherapy backbone regimens

\begin{tabular}{|c|c|c|c|c|}
\hline Chemotherapy regimen & & $<65$ years & $65-75$ years & $\geq 75$ years \\
\hline \multirow[t]{3}{*}{ FOLFOX } & $\mathrm{n}$ & 903 & 394 & 51 \\
\hline & Median PFS (95\% Cl) & $11.2(10.3-12.0)$ & $12.1(10.9-13.4)$ & $11.8(8.9-14.7)$ \\
\hline & Median OS (95\% Cl) & $25.5(22.8-28.1)$ & $30.7(27.6-33.7)$ & not reached \\
\hline \multirow[t]{3}{*}{ XELOX } & $\mathrm{n}$ & 753 & 313 & 25 \\
\hline & Median PFS (95\% Cl) & $11.5(10.6-12.5)$ & $11.5(10.3-12.8)$ & $13.2(10.9-15.5)$ \\
\hline & Median OS (95\% Cl) & $30.0(27.3-32.7)$ & $27.0(23.8-30.2)$ & $25.1(16.6-33.6)$ \\
\hline \multirow[t]{3}{*}{ FOLFIRI } & $n$ & 199 & 74 & 5 \\
\hline & Median PFS (95\% Cl) & $12.2(10.7-13.8)$ & $11.3(9.0-13.6)$ & - \\
\hline & Median OS (95\% Cl) & $25.4(21.5-29.4)$ & $22.9(19.9-25.9)$ & - \\
\hline \multirow[t]{3}{*}{ XELIRI } & $n$ & 127 & 39 & 1 \\
\hline & Median PFS (95\% Cl) & $14.9(12.5-17.2)$ & $11.3(8.4-14.1)$ & - \\
\hline & Median OS (95\% Cl) & $29.1(22.4-35.9)$ & $26.7(19.9-33.6)$ & - \\
\hline \multirow[t]{3}{*}{ Capecitabine } & $\mathrm{n}$ & 39 & 44 & 18 \\
\hline & Median PFS (95\% Cl) & $9.4(6.1-12.7)$ & $10.3(4.1-16.5)$ & $13.4(7.9-18.8)$ \\
\hline & Median OS (95\% Cl) & $31.1(27.0-35.2)$ & $17.0(6.3-27.7)$ & $19.8(11.8-27.9)$ \\
\hline \multirow[t]{3}{*}{ 5-FU/LV } & $n$ & 21 & 21 & 23 \\
\hline & Median PFS (95\% Cl) & $10.1(4.1-16.1)$ & $5.9(3.3-8.5)$ & $10.5(6.9-14.0)$ \\
\hline & Median OS (95\% Cl) & $22.6(14.0-31.2)$ & $21.3(5.4-37.1)$ & $19.4(10.7-28.2)$ \\
\hline
\end{tabular}

metastases had the risk of death increased by $25 \%$ compared to patients with metachronous mCRC.

The multivariable Cox models for PFS and OS were also calculated on the subset of patients with available information on performance status $(n=1,821)$. Similarly to the entire cohort, the patient age was not observed to have significant effect on either PFS or OS (data not shown), whereas the number of metastatic sites and the presence of metastatic disease at diagnosis were confirmed as the strongest prognostic factors with respect to both PFS and OS.

\section{Safety outcomes}

Only bevacizumab-associated toxicity events were reported to the registry. Safety data are summarised in Table 4. As expected, the most common bevacizumab-related adverse

Table 3 Results of the multivariable Cox model for progression-free survival (PFS) and overall survival (OS)

\begin{tabular}{|c|c|c|c|c|c|}
\hline Model for PFS & Risk/baseline category & Beta & HR & $95 \% \mathrm{Cl}$ & p-value \\
\hline \multirow[t]{2}{*}{ Number of metastatic sites } & $2 / 1$ & 0.29 & 1.34 & $1.22-1.46$ & $<0.001$ \\
\hline & 3 and more/1 & 0.53 & 1.70 & $1.50-1.94$ & $<0.001$ \\
\hline Presence of metastasis at diagnosis & $\mathrm{M} 1 / \mathrm{MO}$ & 0.12 & 1.13 & $1.03-1.23$ & 0.008 \\
\hline Site of primary tumour & Rectum/Colon & 0.09 & 1.10 & $1.01-1.19$ & 0.04 \\
\hline \multirow[t]{2}{*}{ Age } & $65-75$ years $/<65$ years & -0.01 & 0.99 & 0.91-1.09 & 0.88 \\
\hline & $>75$ years $/<65$ years & 0.01 & 1.01 & $0.81-1.25$ & 0.96 \\
\hline Model for OS & Risk/baseline category & Beta & HR & $95 \% \mathrm{Cl}$ & p-value \\
\hline \multirow[t]{2}{*}{ Number of metastatic sites } & $2 / 1$ & 0.34 & 1.41 & $1.25-1.59$ & $<0.001$ \\
\hline & 3 and more/1 & 0.66 & 1.94 & $1.65-2.27$ & $<0.001$ \\
\hline Presence of metastasis at diagnosis & $\mathrm{M} 1 / \mathrm{MO}$ & 0.23 & 1.25 & $1.12-1.41$ & $<0.001$ \\
\hline Site of primary tumour & Rectum/Colon & 0.12 & 1.13 & $1.01-1.26$ & 0.03 \\
\hline \multirow[t]{2}{*}{ Age } & $65-75$ years $/<65$ years & -0.02 & 0.98 & $0.87-1.11$ & 0.73 \\
\hline & $>75$ years $/<65$ years & 0.17 & 1.18 & $0.89-1.56$ & 0.24 \\
\hline
\end{tabular}


Table 4 Incidence of bevacizumab-related adverse events

\begin{tabular}{|c|c|c|c|c|c|}
\hline & & $\begin{array}{c}\text { All patients } \\
\begin{array}{c}(n=3,187) \\
n(\%)\end{array}\end{array}$ & $\begin{array}{c}<65 \text { years } \\
(n=2,126) \\
n(\%)\end{array}$ & $\begin{array}{c}65-75 \text { years } \\
(n=932) \\
n(\%)\end{array}$ & $\begin{array}{c}\geq 75 \text { years } \\
(n=129) \\
n(\%)\end{array}$ \\
\hline \multirow[t]{2}{*}{ New or worsening hypertension } & All & $115(3.6)$ & $71(3.3)$ & $34(3.6)$ & $10(7.8)$ \\
\hline & G3-5 & $51(1.6)$ & $31(1.5)$ & $16(1.7)$ & $4(3.1)$ \\
\hline \multirow[t]{2}{*}{ Thromboembolic event } & All & $105(3.3)$ & $65(3.1)$ & $36(3.9)$ & $4(3.1)$ \\
\hline & G3-5 & $82(2.6)$ & $49(2.3)$ & $30(3.2)$ & $3(2.3)$ \\
\hline \multirow[t]{2}{*}{ Proteinuria } & All & $59(1.9)$ & $40(1.9)$ & $17(1.8)$ & $2(1.6)$ \\
\hline & G3-5 & $13(0.4)$ & $8(0.4)$ & $5(0.5)$ & $0(0)$ \\
\hline \multirow[t]{2}{*}{ Bleeding } & All & $40(1.3)$ & $24(1.1)$ & $15(1.6)$ & $1(0.8)$ \\
\hline & G3-5 & $19(0.6)$ & $12(0.6)$ & $7(0.8)$ & $0(0)$ \\
\hline \multirow[t]{2}{*}{ Gastrointestinal perforation } & All & $8(0.3)$ & $5(0.2)$ & $3(0.3)$ & $0(0)$ \\
\hline & G3-5 & $4(0.1)$ & $3(0.1)$ & $1(0.1)$ & $0(0)$ \\
\hline
\end{tabular}

events were hypertension and thromboembolic events. Hypertension was reported in 71 patients (3.3\%), 34 patients $(3.6 \%)$, and 10 patients $(7.8 \%)$ in $<65$ years, 65 to 75 years, and $\geq 75$ years age group, respectively. Thromboembolic event was reported in 65 (3.1\%), 36 (3.9\%), and $4(3.1 \%)$ patients aged $<65$ years, 65 to 75 years, and $\geq 75$ years, respectively. The incidence of both proteinuria and bleeding did not exceed $2.0 \%$ in any age group. Gastrointestinal perforation was recorded in 8 patients ( 5 aged $<65$ years, 3 aged 65 to 75 years). Severe (i.e. grade $\geq 3$ ) adverse events were rarely observed except for hypertension and thromboembolic events, which were, however, reported in less than $4.0 \%$ of patients across all age groups.

\section{Discussion}

The present retrospective observational study using the population-based CORECT registry that included more than 1,000 mCRC patients aged $\geq 65$ years ranks among the largest studies published so far analysing the outcome of treatment with bevacizumab combined with chemotherapy in the elderly patients. Although patients $\geq 65$ years of age represent the majority of patients with $\mathrm{mCRC}$, elderly patients are commonly underrepresented in prospective randomized clinical trials, and, in addition, there are still limited data from observational studies about the efficacy and safety of bevacizumabcontaining therapy in this patient population.

With regard to the survival outcomes, the present analysis shows that elderly $\mathrm{mCRC}$ patients receiving bevacizumab-containing therapy, both 65 to 75 years and $\geq 75$ years age groups, have PFS and OS similar to those of mCRC patients aged $<65$ years. These results were confirmed in both the univariate analysis and in the multivariable Cox model adjusted for possible confounding factors. The observation that patient age does not significantly influence PFS and OS of mCRC patients is consistent with previously published reports [11-14]. Thus, patient age should not be considered a limiting factor with respect to bevacizumab-containing therapy in mCRC patients. The most significant factors with respect to both PFS and OS were the number of metastatic sites and the presence of metastases at diagnosis of CRC.

In this study, the median PFS estimates for all agedefined cohorts were higher than the PFS estimates in the BRiTE observational study [15]. Similarly, agespecific median OS estimates in the present analysis were higher compared to the BRiTE study. These differences can be partly explained by an almost $20 \%$ higher proportion of patients with synchronous metastases in the BRiTE study. In addition, different distribution of ECOG PS categories could also contribute to the differences in OS. While almost all (97.5\%) mCRC patients with recorded performance status information in our cohort had a performance status of 0 or 1 , the respective percentage in the BRiTE cohort was lower (92.4\%). Moreover, the relatively favourable OS results may also be partly attributed to the effective centralisation of mCRC patients into comprehensive cancer centres (CCCs) which has been implemented in the Czech Republic as of 2006 [11]. The administration of the most expensive cancer drugs including bevacizumab is currently concentrated to only 13 CCCs. In comparison, the median number of patients enrolled per centre was only 8 for the 248 sites in the BRiTE study [8].

Other findings regarding the administration and outcomes of anti-tumour therapy in elderly mCRC patients were consistent with the BRiTE study. As for chemotherapy backbone regimens, the elderly patients received, in general, less aggressive therapy, and both oxaliplatin and irinotecan were administered less often 
in $\mathrm{mCRC}$ patients $>65$ years of age than in younger patients. In addition, the overall duration of treatment was shorter in the elderly $\mathrm{mCRC}$ population compared to younger patients [15]. The tendency to administer less aggressive and shorter therapy can be justified by the fact that the elderly mCRC patients were reported to experience significantly greater hematologic toxicity [17].

Regarding patients $\geq 75$ years of age who were treated with bevacizumab and capecitabine only, the results can be compared with data of the AGITG MAX trial [14] and the AVEX trial [18]. In this analysis, we observed higher median PFS estimate and similar median OS estimate compared with the corresponding estimates published in the two trials (Table 2). However, the difference in PSF should be assessed with caution as only 18 patients were included in the present analysis resulting in high variability of the estimate.

Present results cannot be compared to the Surveillance, Epidemiology, and End Results-Medicare linked database analysis of Meyerhardt et al. [19] that evaluated the effectiveness of first-line bevacizumab-containing therapy in stage IV CRC patients aged $>65$ years. Firstly, a different time period was evaluated in the U.S. study (mCRC patients diagnosed in 2007 or earlier). Secondly, only patients diagnosed with stage IV CRC (synchronous metastases) were analysed and, thirdly, only patients treated with either oxaliplatin- or irinotecan-based chemotherapy were considered by Meyerhardt et al.

Among the major bevacizumab-related toxicities, new or worsening hypertension, thromboembolic events, and proteinuria have been reported in $\geq 10 \%$ of patients receiving bevacizumab $[13,15,20,21]$. Moreover, the incidence of hypertension was also found to be age-related [22]. Bleeding, gastrointestinal perforations, and wound healing complications were observed less often [23]. In the present study, the above mentioned adverse events were recorded less frequently than in previously reported (Table 4). Underreporting cannot be obviously excluded in the registry. On the other hand, when considering severe adverse events only (grade $\geq 3$ ); the results of the present study are more consistent with those of other reports. This implies that serious adverse events or events leading to the treatment interruption or modification were more likely to be reported to the database. Despite the lower incidence of adverse events, however, no increase in bevacizumab-related toxicity among the elderly mCRC patients was observed, the only exception being hypertension, which occurred in approximately twice as many patients aged $\geq 75$ years in comparison with patients in $<65$ years and 65 to 75 years age groups.

The present analysis has several limitations that can be partly attributable to its observational nature. First and foremost, the selection bias cannot be excluded as only medically fit patients with very good performance status might have been treated with bevacizumab-containing therapy among the elderly mCRC patients in contrast to younger patients where indication criteria tend to be less strict. This is suggested by the low proportion of elderly patients in the whole cohort of bevacizumab-treated patients and in turn might have led to more favourable OS estimate in elderly patients. In fact, while patients aged $\geq 65$ years represent the majority of $\mathrm{mCRC}$ population (64\% of newly diagnosed mCRC patients in 20062010 according to the Czech National Cancer Registry [2]), in the present analysis only about a third of the patients were aged $\geq 65$ years. Secondly, the PFS estimates could have been biased by the fact that neither independent monitoring nor centralized review of radiological response was performed in our study. Last but not least, in comparison with other clinical and observational studies, the adverse events seem to be underreported in the study database. Moreover, only adverse events thought to be linked to bevacizumab were consistently reported in the registry. Although many countries have now implemented some degree of centralisation of treatment and decisionmaking in the area of targeted cancer therapies, the results presented here may not be fully generalisable to more decentralised health systems. Nevertheless, the 5-year relative survival of patients diagnosed with stage IV colorectal cancer was $11.5 \%$, a figure similar to European and US data [24-26].

\section{Conclusions}

The present large retrospective study confirms that a selected group of elderly mCRC patients fit for chemotherapy combined with targeted therapy may derive similar benefit in terms of improvement in OS and PFS from bevacizumab therapy compared to younger patients. Thus, chronological age should not be considered an exclusion criterion for bevacizumab-containing therapy in $\mathrm{mCRC}$.

\section{Competing interests}

JT, TB, BM, and JF have received speakers' honoraria from Roche. All other authors state that they have no conflicts of interest.

\section{Authors' contributions}

LS and TP designed the study, performed the statistical analysis, and wrote the manuscript; LD designed the study and participated in the manuscript writing and in the interpretation of results; $\mathrm{ZB}$ and $\mathrm{OM}$ participated in the statistical analysis; JT, TB, BM, RV, JP, and JF validated input data as expert oncologists and participated in the interpretation of results and reviewed the manuscript. All authors read and approved the final manuscript.

\section{Acknowledgements}

The CORECT database maintenance is supported by unrestricted research grants from Roche, Merck, and Amgen. The funding bodies had no role in design, collection, analysis or interpretation of the data, writing of the manuscript or the decision to submit the manuscript for publication.

\section{Author details}

${ }^{1}$ Department of Oncology, Hospital Jihlava, Jihlava, Czech Republic. ${ }^{2}$ Institute of Biostatistics and Analyses, Masaryk University, Brno, Czech Republic.

${ }^{3}$ Department of Comprehensive Cancer Care, Masaryk Memorial Cancer Institute, Brno, Czech Republic. ${ }^{4}$ Department of Oncology and First Faculty of 
Medicine, Charles University and Thomayer Hospital, Prague, Czech Republic. ${ }^{5}$ Department of Oncology, Palacky University Medical School and Teaching Hospital, Olomouc, Czech Republic. ${ }^{6}$ Department of Oncology, Motol Hospital and Charles University, Prague, Czech Republic. ${ }^{7}$ Department of Oncology, University Hospital Pilsen, Pilsen, Czech Republic.

Received: 12 December 2013 Accepted: 19 March 2014 Published: 25 March 2014

\section{References}

1. Ferlay J, Shin HR, Bray F, Forman D, Mathers C, Parkin DM: GLOBOCAN 2008, Cancer Incidence and Mortality Worldwide. IARC CancerBase No. 10. Lyon: International Agency for Research on Cancer; 2010. Available from: http:// globocan.iarc.fr.

2. Dušek L, Mužík J, Kubásek M, Koptíková J, Zaloudík J, Vyzula R: Epidemiology of malignant tumours in the Czech Republic. [http://www.svod.cz]

3. Kopetz S, Chang GJ, Overman MJ, Eng C, Sargent DJ, Larson DW, Grothey A, Vauthey JN, Nagorney DM, McWilliams RR: Improved survival in metastatic colorectal cancer is associated with adoption of hepatic resection and improved chemotherapy. J Clin Oncol 2009, 27:3677-3683.

4. Peeters $\mathrm{M}$, Price T: Biologic therapies in the metastatic colorectal cancer treatment continuum-applying current evidence to clinical practice. Cancer Treat Rev 2012, 38:397-406.

5. Hurwitz H, Fehrenbacher L, Novotny W, Cartwright T, Hainsworth J, Heim W, Berlin J, Baron A, Griffing S, Holmgren E, Ferrara N, Fyfe G, Rogers B, Ross R, Kabbinavar F: Bevacizumab plus irinotecan, fluorouracil and leucovorin for metastatic colorectal cancer. N Engl J Med 2004, 250:2335-2342.

6. Kabbinavar FF, Hambleton J, Mass RD, Hurwitz HI, Bergsland E, Sarkar S: Combined analysis of efficacy: the addition of bevacizumab to fluorouraci//leucovorin improves survival in patiens with metastatic colorectal cancer. J Clin Oncol 2005, 23:3706-3712.

7. Saltz LB, Clarke S, Díaz-Rubio E, Scheithauer W, Figer A, Wong R, Koski S, Lichinitser M, Yang TS, Rivera F, Couture F, Sirzén F, Cassidy J: Bevacizumab in combination with oxaliplatin-based chemotherapy as first-line therapy in metastatic colorectal cancer: a randomized phase III study. J Clin Oncol 2013-2019, 2008:26.

8. Kozloff M, Yood MU, Berlin J, Flynn PJ, Kabbinavar FF, Purdie DM, Ashby MA Dong W, Sugrue MM, Grothey A, Investigators of the BRiTE study: Clinical outcomes associated with bevacizumab-containing treatment of metastatic colorectal cancer: the BRiTE observational cohort study. Oncologist 2009, 14:862-870.

9. Van Cutsem E, Rivera F, Berry S, Kretzschmar A, Michael M, DiBartolomeo M, Mazier MA, Canon JL, Georgoulias V, Peeters M, Bridgewater J, Cunningham D; First BEAT investigators: Safety and efficacy of first-line bevacizumab with FOLFOX, XELOX, FOLFIRI and fluoropyrimidines in metastatic colorectal cancer: the BEAT study. Ann Oncol 1842-1847, 2009:20.

10. Hutchins LF, Unger JM, Crowley JJ, Coltman CA Jr, Albain KS: Underrepresentation of patients 65 years of age or older in cancer-treatment trials. N Engl J Med 2061-2067, 1999:341.

11. Dusek L: Czech Cancer Care in Numbers 2008-2009. Praque: Grada Publishing; 2009

12. Kabbinavar FF, Hurwitz HI, Yi J, Sarkar S, Rosen O: Addition of bevacizumab to fluorouracil-based first-line treatment of metastatic colorectal cancer: pooled analysis of cohorts of older patients from two randomized clinical trials. J Clin Oncol 2009, 27:199-205.

13. Cassidy J, Saltz LB, Giantonio BJ, Kabbinavar FF, Hurwitz HI, Rohr UP: Effect of bevacizumab in older patients with metastatic colorectal cancer: pooled analysis of four randomized studies. J Cancer Res Clin Oncol 2010, 136:737-743.

14. Price TJ, Zannino D, Wilson K, Simes RJ, Cassidy J, Van Hazel GA, Robinson BA Broad A, Ganju V, Ackland SP, Tebbutt NC: Bevacizumab is equally effective and no more toxic in elderly patients with advanced colorectal cancer: a subgroup analysis from the AGITG MAX trial: an international randomised controlled trial of Capecitabine, Bevacizumab and Mitomycin C. Ann Oncol 2012, 23:1531-1536.

15. Kozloff MF, Berlin J, Flynn PJ, Kabbinavar F, Ashby M, Dong W, Sing AP, Grothey A: Clinical outcomes in elderly patients with metastatic colorectal cancer receiving bevacizumab and chemotherapy: results from the BRiTE observational cohort study. Oncology 2010, 78:329-339.

16. Němeček $R$, Tomášek J, Hejduk K, Bortlíček Z: Klinický registr CORECT. Klin onkol 2012, 25:480-485.
17. Goldberg RM, Tabah-Fisch I, Bleiberg H, de Gramont A, Tournigand C, Andre T, Rothenberg ML, Green E, Sargent DJ: Pooled analysis of safety and efficacy of oxaliplatin plus fluorouracil/leucovorin administered bimonthly in elderly patients with colorectal cancer. J Clin Oncol 2006, 24:4085-4091.

18. Cunningham D, Lang I, Marcuello E, Lorusso V, Ocvirk J, Shin DB, Jonker D, Osborne S, Andre N, Waterkamp D, Saunders MP, AVEX study investigators: Bevacizumab plus capecitabine versus capecitabine alone in elderly patients with previously untreated metastatic colorectal cancer (AVEX): an open-label, randomised phase 3 trial. Lancet Oncol 2013, 14:1077-1085.

19. Meyerhardt JA, Li L, Sanoff HK, Carpenter W, Schrag D: Effectiveness of bevacizumab with first-line combination chemotherapy for Medicare patients with stage IV colorectal cancer. J Clin Oncol 2012, 30:608-615.

20. Zhu X, Wu S, Dahut WL, Parikh CR: Risks of proteinuria and hypertension with bevacizumab, an antibody against vascular endothelial growth factor: systematic review and meta-analysis. Am J Kidney Dis 2007, 49:186-193.

21. Tsai HT, Marshall JL, Weiss SR, Huang CY, Warren JL, Freedman AN, Fu AZ, Sansbury LB, Potosky AL: Bevacizumab use and risk of cardiovascular adverse events among elderly patients with colorectal cancer receiving chemotherapy: a population-based study. Ann Oncol 2013, 24:1574-1579.

22. Aprile G, Ferrari L, Fontanella C, Puglisi F: Bevacizumab in older patients with advanced colorectal or breast cancer. Crit Rev Oncol/Hematol 2013, 87:41-54.

23. Kyriakou F, Kountourakis P, Papamichael D: Targeted agents: review of toxicity in the elderly metastatic colorectal cancer patients. Target Oncol 2011, 6:245-251

24. Pavlík T, Májek O, Büchler T, Vyzula R, Petera J, Ryska M, Ryška A, Cibula D, Babjuk M, Abrahámová J, Vorliček J, Mužík J, Dušek L: Trends in stage-specific population-based survival of cancer patients in the Czech Republic in the period 2000-2008. Cancer Epidemiol 2014, 38:28-34.

25. Brenner $\mathrm{H}$, Gondos $\mathrm{A}$, Arndt V: Recent major progress in long-term cancer patient survival disclosed by modeled period analysis. J Clin Oncol 2007, 25:3274-3280.

26. Allemani C, Rachet B, Weir HK, Richardson LC, Lepage C, Faivre J, Gatta G, Capocaccia R, Sant M, Baili P, Lombardo C, Aareleid T, Ardanaz E, Bielska-Lasota M, Bolick S, Cress R, Elferink M, Fulton JP, Galceran J, Gózdz S, Hakulinen T, Primic-Zakelj M, Rachtan J, Diba CS, Sánchez MJ, Schymura MJ, Shen T, Tagliabue G, Tumino R, Vercelli M, et al: Colorectal cancer survival in the USA and Europe: a CONCORD high-resolution study. BMJ Open. in press.

\section{doi:10.1186/1471-230X-14-53}

Cite this article as: Slavicek et al: Efficacy and safety of bevacizumab in elderly patients with metastatic colorectal cancer: results from the Czech population-based registry. BMC Gastroenterology 2014 14:53.

\section{Submit your next manuscript to BioMed Central and take full advantage of:}

- Convenient online submission

- Thorough peer review

- No space constraints or color figure charges

- Immediate publication on acceptance

- Inclusion in PubMed, CAS, Scopus and Google Scholar

- Research which is freely available for redistribution 